\title{
The influence of carbon particle type in fly ashes on mercury adsorption
}

M. Antonia López-Antón, Patricia Abad-Valle, Mercedes Díaz-Somoano, Isabel Suárez-Ruiz and M. Rosa Martínez-Tarazona

Instituto Nacional del Carbón (CSIC). C/ Francisco Pintado Fe, 26, 33011, Oviedo, Spain

*Corresponding author. Telephone +34 985119090; Fax +34 985297662

E-Mail address: rmtarazona@incar.csic.es 


\begin{abstract}
Recent research has shown that certain fly ash materials produced in coal combustion for power generation have an affinity for the mercury compounds present in flue gases. However, the exact nature of Hg-fly ash interactions is still unknown and the different variables that influence mercury adsorption need to be identified. In this work the microscopic components of fly ashes derived from the combustion of different types of feed blends of different coal rank and mercury adsorption were investigated. The aim of this research was to establish relationships between $\mathrm{Hg}$ retention and the type of unburned carbons present in various fly ashes. The fly ashes and fly ash fractions studied were used as sorbent beds for high mercury concentrations, conditions in which mercury retention is highly favored. From the results obtained it was confirmed that the role of the unburned carbon components in mercury capture may depend, among other factors, on the type of unburned carbon. Fly ashes capture different species of mercury depending on their nature and the type of anisotropic particles.
\end{abstract}

Keywords: mercury; fly ash; unburned carbon 


\section{Introduction}

Mercury in coal and its emissions from coal-fired boilers is a topic of primary environmental concern in the United States [1] and also in Europe [2]. During combustion, most of the mercury present in coal evades capture in power plant emission control systems and remains predominantly in gaseous form even at stack temperatures [3-5]. As a consequence coal fired power plants are one of the main sources of mercury emission to the environment [1]. Although various control technologies have been investigated, until now no cost-effective or efficient control process has been developed for mercury removal in coal power stations. Interest in developing such systems has encouraged several research groups to acquire a fundamental knowledge that may contribute to understanding i) the maximum level of retention achievable by the subproducts originated in combustion plants, and ii) the influence of these sub-products on the behavior of other sorbents employed for mercury capture. It has been observed that the sub-products originated in FGD (flue gas desulphurization) systems and fly ashes capture mercury in different proportions depending on their characteristics and on the process conditions. In fact, power stations equipped with SCR DeNOx and FGD systems are able to capture significant quantities of mercury as a consequence of $\mathrm{Hg}$ oxidation in SCR DeNOx that may be subsequently captured in FGD systems [6]

The retention of hazardous elements by fly ashes produced in combustion plants has been extensively studied in recent years. In the case of mercury it has been observed that some fly ashes may capture this element which would otherwise be emitted to the atmosphere. Although the role of inorganic components of fly ashes in this capture is still unclear, great attention has been paid to the capture of mercury by unburned fly ash carbons [7-14]. A relationship has been reported between $\mathrm{Hg}$ content and the percentage of carbon in fly ashes derived from the combustion of bituminous coals [9] and coal 
blends containing anthracites [14-15]. The role that the different types of unburned carbons play in mercury capture in fly ashes has also been a matter of interest with some studies associating the types of particles with the amount of $\mathrm{Hg}$ captured [9, 14-15]. The concentration of unburned carbons and their respective ability to capture $\mathrm{Hg}$ have also been related to their textural properties [9, 15-17] given that the BET surface area successively increased from inertinite, isotropic coke (isotropic fly ash carbons) to anisotropic coke (anisotropic fly ash carbons) [9].

In view of the significant variations in the properties of fly ashes obtained from different coals $[15,18-19]$ and to obtain a better understanding of the properties of the materials that influence the capture of $\mathrm{Hg}$, we have tried to establish a relationship between $\mathrm{Hg}^{0}$ and $\mathrm{HgCl}_{2}$ retention and the characteristics of fly ash samples taken from the combustion of feed coal blends of different characteristics. This study is part of a broader work carried out in a laboratory scale reactor that aims to clarify the influence

of several variables on mercury capture in fly ashes $[11,20]$.Data on the proportions of different types of carbon particles present in fly ashes were studied together with the ability of these materials to retain high concentrations of mercury in a laboratory scale reactor in which the ashes were used as fixed beds. To improve the possible effect of such particles, they were concentrated by sieving. The fractions enriched in carbon particles were also used as sorbents for mercury. The relationship between the types of particles, the BET surface area and the quantities of mercury retained was studied.

\section{Experimental}

The four fly ash samples from different power stations used in this study have already been described in previous works $[11,20]$. Three of them were obtained from pulverized coal combustion power plants (PCC), while the fourth was taken from a 
fluidized coal combustion power plant (FBC). The fuels burned in these power stations were coal blends of different origin i) containing mainly high rank coals (CTA) ii) bituminous coals (CTSR) and iii) subbituminous coals (CTES). The CTP fly ash was taken from the FBC plant that burned a blend of bituminous coal and coal wastes mixed with limestone. The combustion temperature in the four pulverized coal power stations was higher than $1300^{\circ} \mathrm{C}$. These plants have electrostatic precipitators as particle control devices but none of them are fitted with flue gas desulphurization systems. Fly ashes from the precipitator were sampled in all cases. The temperature in the fluidized combustion bed of the power station from which CTP sample was obtained was close to $850^{\circ} \mathrm{C}$

In order to obtain an unburned particle carbon concentrate from each fly ash, size fractionation of the fly ashes was carried out by dry and wet sieving. Before obtaining the fly ash fractions enriched in unburned particles a preliminary fractionation study was carried out by sieving. The number of fractions (between 10 and 12) and the size range of each one (minimum $12 \mathrm{~mm}$ and maximum of $500 \mathrm{~mm}$ ) was different for each fly ash sample. Wet sieving was carried out on the samples lower than $150 \mathrm{~mm}$ whereas dry sieving was used on those larger than $150 \mathrm{~mm}$. Cumulative weight and LOI values were evaluated to select the cutting point for obtaining the fractions enriched in unburned particle content. These fractions were CTA>150 mm, CTSR $>80 \mathrm{~mm}$ and CTES $>200 \mathrm{~mm}$. In the case of CTP the unburned particles were homogeneously distributed among all the sizes. In the CTA, CTSR and CTES samples, unburned carbon particles were concentrated in fractions of a large particle size. CTA $>150 \mu \mathrm{m}$, CTSR $>80 \mu \mathrm{m}$ and CTES $>200 \mu \mathrm{m}$ were the fractions used as unburned carbon concentrates. In the case of CTP only the raw sample was employed in this study 
because the amount of unburned particles was homogeneously distributed among all sizes.

Loss of ignition (LOI) in the raw fly ashes and fractions concentrated in unburned particles was determined by the combustion of the organic matter in air at $815^{\circ} \mathrm{C}$. The BET surface area was determined by volumetric adsorption of nitrogen at $77 \mathrm{~K}$. The composition of the fly ashes in terms of organic and inorganic components and the textural and morphological characteristics of the particles were analyzed by optical microscopy. Fly ash samples were prepared for petrographic analysis following a modified procedure described in the ISO 7404/2 Norm. A point counting analysis was carried out following the ISO $7404 / 3$ norm to obtain the percentages of microscopic components present in the raw ash samples and in the ash fractions. In this case polarized light and a retarded plate incorporated into the microscope system was used during the analysis for a better definition of their optical texture. Microphotographs of fly ash carbons were taken on a Zeiss Axioplan Microsope using a Leica software to capture and analyze the images. Raman analysis was performed by means of a HR 800 Jobin Yvon Horiba microspectrometer. A $514.5 \mathrm{~nm}, 25 \mathrm{~mW} \mathrm{Ar}{ }^{+}$laser was used as excitation source. Two bands in the first-order region were detected: the $G$ band (graphite) at $\sim 1600 \mathrm{~cm}^{-1}$ and the D band (defects) at $\sim 1355 \mathrm{~cm}^{-1}[20]$.

The experimental device used for the retention experiments at laboratory scale has been described in preliminary works $[11,20]$. The experimental device used for the retention experiments at laboratory scale consisted of a glass reactor fitted with an internal and external tube and heated by two furnaces (Fig 1). $\mathrm{Hg}^{0}(\mathrm{~g})$ and $\mathrm{HgCl}_{2}(\mathrm{~g})$ in the gas atmosphere were obtained by the evaporation of $\mathrm{Hg}^{0}$ and $\mathrm{HgCl}_{2}$ respectively. The experimental procedure for mercury capture was designed to evaluate the retention capacities of fly ashes using higher concentrations of mercury $\left(0.4 \mu \mathrm{g} \mathrm{ml}^{-1}\right)$ than might 
be expected in a coal. The temperature of evaporation was calibrated to obtain mercury concentrations in gas phase of $0.4 \mu \mathrm{g} \mathrm{ml}^{-1}$. The evaporation temperature for $\mathrm{Hg}^{0}$ and $\mathrm{HgCl}_{2}$ was $190^{\circ} \mathrm{C}$. The sorbent bed was made up of $1 \mathrm{~g}$ of fly ash and $3 \mathrm{~g}$ of sand. The sorbent bed and the element source were placed inside the same internal tube but heated separately in two furnaces. A synthetic gas mixture containing $15 \% \mathrm{CO}_{2}, 9.2 \% \mathrm{O}_{2}$, $0.2 \% \mathrm{SO}_{2}, 6.6 \% \mathrm{H}_{2} \mathrm{O}$ and balanced with $\mathrm{N}_{2}$ was passed through the reactor, The gas mixture carried the element compound in vapour phase through the sorbent bed at a flow rate of $0.5 \mathrm{~L} \mathrm{~min}^{-1}$ until fly ash saturation. The time necessary to achieve the maximum retention capacity of the sorbent varied from fly ash to fly ash and ranged from 5 hours for CTP to 28 hours for CTS. The temperature of the sorbent was $120^{\circ} \mathrm{C}$. The element that could not be retained in the sorbent bed was captured in impingers containing $4 \% \mathrm{KMnO}_{4}+10 \% \mathrm{H}_{2} \mathrm{SO}_{4}$ and $\mathrm{HNO}_{3} 0.5 \mathrm{~N}$. The amount of mercury retained was determined by analysing the fly ashes post-retention by means of cold vapour atomic absorption (CV-AA) after mercury extraction with $60 \%(\mathrm{v} / \mathrm{v}) \mathrm{HNO}_{3}$.

\section{Results and discussion}

The LOI, BET surface area, and the $\mathrm{I}_{\mathrm{D}} / \mathrm{I}_{\mathrm{D}}+\mathrm{I}_{\mathrm{G}}$ ratios from the Raman spectra are presented in Table 1. Mercury retention values determined as the maximum amount of element captured in the fly ash (mg of mercury per $\mathrm{g}$ of fly ash) $[11,20]$, are also shown in Table 1. The petrographic composition of fly ashes is given in Table 2.

From the results in Table 1 it can be seen that the fly ashes exhibit different retention capacities depending on the species in gas phase $\left(\mathrm{Hg}^{0}\right.$ or $\left.\mathrm{HgCl}_{2}\right)$. $\mathrm{A}$ comparison of the results obtained demonstrates that $\mathrm{Hg}^{0}$ is retained in fly ashes in a greater proportion than $\mathrm{HgCl}_{2}$ with two exceptions, the CTP and the raw CTES fly 
ashes. When $\mathrm{Hg}^{0}$ is the species in gas phase the retention capacity of the CTSR fly ash reached a value of $25 \mathrm{mg} \mathrm{g}^{-1}$ compared to $12 \mathrm{mg} \mathrm{g}^{-1}$ for $\mathrm{HgCl}_{2}$. These differences are even more significant for the CTA fly ash sample. When the raw fly ash samples are compared with the fractions enriched in unburned carbons it can be observed that retention capacity increases slightly as the unburned carbon content (LOI) rises, the exception being the CTES fly ash from PCC.

The relative intensities of the $\mathrm{D}\left(I_{D}\right)$ and $\mathrm{G}\left(I_{G}\right)$ Raman bands of the carbon materials give an indication of their in-plane structural order [21]. In fact, the $I_{D} / I_{D}+I_{G}$ ratio has been used to account for differences in structural order in carbon materials [22]. For this reason the Raman analysis was only performed on the fly ashes with the highest unburned carbon content. Values of $I_{D} / I_{D}+I_{G}$ averaged from at least 21 measurements for each fly ash are presented in Table 1 . These values are typical of carbon materials with a low level of structural order [23]. The reason why the ratio was similar for all the fly ashes may be due the fact that the predominant unburned particles are those of the anisotropic type (Table 2).

The microscopic components present in the different fly ashes were classified into two groups; organic and inorganic (Table 2). In accordance with previously defined classifications [14], the unburned particles were differentiated as unburned carbons derived exclusively from coal combustion and other organics that include unburned carbons derived from petroleum coke, natural coke and unburned coal. The classification of the various types of unburned carbons was based on genetic and textural criteria [14] such as: i)- the anisotropic / isotropic texture of a specific particle; ii)- fused / un-fused character; and iii)- structure and morphology of the unburned carbons such as massive/dense particles, vesiculate and with porosity, irregular particles, etc., and iv)- origin from coal or other materials. This arrangement is useful 
for classifying all the possible unburned carbons present in fly ashes and derived from the combustion of feed blends of different coal rank, as is demonstrated in the present work. The unburned carbons derived from coal combustion may be anisotropic or isotropic particles, but the category of other organics in this work was mainly of an anisotropic character. The inorganic fraction was classified according to the categories previously reported [24].

CTA is a fly ash mainly derived from the combustion of high rank coals, mainly anthracites with smaller quantities of semi-anthracites and bituminous coals. This is confirmed by the type of unburned carbons identified in the fly ash samples. The predominant components are anisotropic but if one takes into account the rank of the burned feed coals, these anisotropic carbons are unfused and dense particles derived from anthracitic vitrinite. In these ash samples the fused, porous and vesiculated structures are mainly derived from the combustion of inertinite (Table 2). Compared to other types of unburned carbons, the CTA fly ash has low isotropic carbon particle content and a small percentage of coke particles. The predominant fraction in all the fly ashes is the inorganic fraction which is mainly composed of glassy (alumino silicates) material (65-70 \% vol.). Variable amounts of other inorganic materials were also found.

In the case of the CTSR fly ash the unburned carbons are mainly composed of anisotropic particles. The most significant difference with respect to the CTA fly ash is that in the CTSR ash samples the anisotropic carbons are dominated by fused, porous and vesiculated structures made up of cenospheric (0.67-11.0\% vol.) and network (4.7$12.3 \%$ vol.) particles. This type of particles may constitute $58.0 \%$ vol of the total amount of anisotropic components in the fraction CTSR $>80 \mu \mathrm{m}$, while in the CTA samples, the percentage of anisotropic and fused carbons with respect to the anisotropic carbons is lower $(<3.1 \%$ vol.) (Table 2$)$. These unburned carbons are typical of the 
combustion of bituminous coals. The isotropic particles in CTSR are minor components. The type of inorganics is similar to that of the CTA fly ash.

The unburned carbon particles of CTES are dominated by isotropic structures, which are mainly fused and by porous structures derived from lower rank vitrinites (Table 2). These particles are typical of unburned carbons derived from the combustion of low rank coals. In addition, some anisotropic fused carbons (5.4-10.1\% vol.) were present in this sample. The other unburned carbons found in these ashes were present in relatively low amounts. Of the inorganic components, the presence of quartz is significant as well as the amount of other mineral matter that includes undifferentiated mineral matter, probably spinels, etc.

As expected, the amount of unburned carbons differs in each separated sized fraction (Tables 1-2) and the relative increase in unburned particles differs for each ash sample. In the CTSR $>80$ sample, the LOI value is 8 times greater than in the CTSR raw sample (Table 1), while the anisotropic porous structures increase 5 times (Table 2). However, in the CTES $>200$, the LOI value is 9 times greater than in the CTES raw ash whereas that of the anisotropic porous structures is only 2 times larger (Tables 1-2).

Finally, the type and amount of unburned carbons in the CTP fly ash sample (from FBC) are completely different to the composition of the fly ash samples derived from the combustion of pulverized feed coal blends (Table 2). The CTP fly ash is mainly composed of anisotropic undifferentiated fragments $(<25 \mu \mathrm{m})$ although traces of fused and un-fused anisotropic particles from the combustion of bituminous coals were also found. A higher amount of oxides than that of the fly ashes from PCC was detected in the CTP inorganic fraction (28.5\% vol.).

The mercury values recorded were compared to the content of each type of organic component and total inorganic matter present in the fly ashes, the most 
significant of which are given in Fig 2-3. Because mercury retention depends on the mode of occurrence of this element in gas phase the evaluation was based on each individual mercury species. When the retention of $\mathrm{Hg}^{0}$ was compared to the amount of each type of unburned carbons in the fly ashes, no correlations were found (Fig 2). However, a general tendency could be observed with the anisotropic, fused and porous structures (which are mainly network structures in all cases). Fig 4 shows two examples of anisotropic fly ash carbons: i) an unfused and massive structure (Fig 4a) and ii) a fused and porous structure (Fig 4b). The highest mercury capture occurred in the CTSR $>80$ fly ash which has the maximum amount of anisotropic fused structures $(23.0$ $\%$ vol.), but a similar $\mathrm{Hg}^{0}$ retention was found in the raw CTSR fly ash with $5.33 \%$ vol. of these structures (Figure 1). As observed in previous works there is no relationship between the total amount of isotropic components [14-15], the total amount of mineral matter and the mercury retained (Fig 2). Similarly, when the retention of $\mathrm{HgCl}_{2}$ is evaluated, it can be observed that the retention of this species varies considerably for each fly ash sample (Table 1). A comparison between the mercury captured when $\mathrm{HgCl}_{2}$ is the species evaporated and the type of fly ash carbons present in these fly ashes was also made, the most valuable results of which are shown in Figure 2. The mercury retained as $\mathrm{HgCl}_{2}$ follows a similar behavior to $\mathrm{Hg}$ with respect to the different types of anisotropic particles, isotropic components and total mineral matter content.

Although the surface area values (Table 1) are very low compared to those of the microporous materials, the results obtained in this work and other works $[14,25]$ suggest that they may be significant enough to have an influence on mercury capture. Broadly speaking, the samples that have a greater surface area retain a higher quantity of $\mathrm{HgCl}_{2}$, but this tendency shows several exceptions in the case of $\mathrm{Hg}$ (Fi 5). 


\section{Conclusions}

The results obtained in a laboratory scale reactor in which the ashes were used as fixed beds suggest that the carbon present in fly ashes influence the retention of different mercury species in gas phase, as can be seen by comparing retention in a given fly ash and in a fraction concentrated in unburned particles. However, this influence is not the only mechanism that controls mercury capture, as can be observed by comparing different fly ashes. The role of unburned carbon components, such as anisotropic, fused and porous structures in mercury capture is not clear. However, fly ashes may capture different species of mercury depending on the nature of these species and some variations may be due to the type of anisotropic particles

\section{Acknowledgements}

The results of this work were obtained as part of the projects PPQ2001-2359-C02-02 and CTM2004-04252.CO2-02/TECNO

\section{References}

[1]U.S. Environmental Protection Agency, Mercury http://www.epa.gov/mercury

[2] http://europa.eu.int/comm/environment/chemicals/mercury/index.htm

[3]Senior LC. $21^{\text {st }}$ Century: Impacts of Fuel Quality and Operations, Engineer. Found. Confer., 2001; pp 17.

[4]Ghorishi SB, Sedman CB. Low concentration mercury sorption mechanism and control by calcium-based sorbents: application in coal-fired processes. J Air Waste Manage 1998; 48:1191-8. 
[5]Ghorishi SB, Keeney RM, Serre SD, Gullett BK, Jozewicz WS. Development of a Cl-impregnated activated carbon for entrained-flow capture of elemental mercury. Environ Sci Technol 2002; 36:4454-9.

[6]Meij R., Vredenbregt LHJ, Winkel HT The fate and behaviour of mercury in coalfired power plants. Journal of the Air \& Waste Management Association 200252 912-7 [7]Pavlish JH, Sondreal EA, Mann MD, Olson ES, Galbreath KC, Laudal DL et al. Status review of mercury control options for coal-fired power plants. Fuel Proc Technol $2003 ; 82(2-3): 89-165$.

[8]Sakulpitaphon T, Hower JC, Trimble AS, Schram WH, Thomas GA. Arsenic and mercury partitioning in fly ash at a Kentucky Power Plant. Energ Fuel 2003; 17:102833.

[9]Hower JC, Maroto-Valer MM, Taulbee DN, Sakulpitakphon T. Mercury capture by distinct fly ash carbon forms. Energ Fuel 2000; 14:224-6.

[10]Hower JC, Robl TL, Anderson C, Thomas GA, Sakulpitakpton T, Mardon S et al. Characteristics of coal combustion products (CCP's) from Kentucky power plants, with emphasis on mercury content. Fuel 2005; 84:1338-50

[11]López-Antón MA, Díaz-Somoano M, Martínez-Tarazona MR. Mercury retention by fly ashes from coal combustion: Influence of the unburned coal content. Ind Eng Chem Res 2007; 46:927-31

[12]Sloss LL. Mercury emissions and effects-The role of coal. IEA Coal Research IEAPER/19, 1995; pp 39.

[13]Li Z, Luo X, Hwang JY. Unburned carbons from fly ash for mercury adsorption II: Adsorption Isotherms and Mechanisms. J Min Mat Cgara Eng 2002; 1:79-96. 
[14]Suárez-Ruiz I, Hower JC, Thomas GA. Hg and Se capture and fly ash carbons from combustion of complex pulverized feed blends mainly of anthracitic coal rank in Spanish power plants. Energ Fuel 2007; 21:59-70

[15]Suárez-Ruiz I, Parra JB. Relationship between the textural properties, fly ash carbons and $\mathrm{Hg}$ capture in fly ashes derived from the combustion of anthracitic pulverized feed blends. Energ Fuel 2007 (in press)

[16]Maroto-Valer MM, Taulbee DN, Hower JC. Characterization of differing forms of unburned carbon present in fly ash separated by density gradient centrifugation. Fuel $2001 ; 80: 795-800$

[17]Maroto-Valer MM, Taulbee DN, Hower JC. Novel separation of the differing forms of unburned carbon present in fly ash using density gradient centrifugation. Energ Fuel $1999 ; 13: 947-53$

[18]Baltrus JP, Wells AW, Fauth DJ, Diehl JR, White CM. Characterization of carbon concentrates from coal-combustion fly ash. Energ Fuel 2001; 15:455-62

[19]Kulaots I, Hurt RH, Suuberg EM. Size distribution of unburned carbon in coal fly ash and its implications. Fuel 2004; 83:223-30

[20]López-Antón MA, Díaz-Somoano M, Martínez-Tarazona MR. Retention of elemental mercury in fly ashes in different atmospheres. Energ Fuel 2007; 21:99-103

[21]Tuinstra F, Koening JL. Characterization of graphite fiber surfaces with Raman spectroscopy. J Comp Mat, 1970; 4:492-9.

[22]Montes-Morán MA, Young RJ. Raman spectroscopy study of HM carbon fibres: effect of plasma treatment on the interfacial properties of single fibre/epoxy composites. Carbon 2002; 40:845-55

[23]Lespade P, Marchand A, Couzi M, Cruege F. Caracterisation de materiaux carbones par microspectrometrie raman. Carbon 1984, 22:375-85 
[24]Hower JC, Suárez-Ruiz I, Mastalerz M. An approach towards a combined scheme for petrographic classification of fly ash: revision and classification. Energ Fuel 2005; 19:653-5.

[25]Dunham GE, DeWall RA, Senior C.L. Fixed-bed studies of the interactions between mercury and coal combustion fly ash. Fuel Process Technol 2003; 82:197-213. 
Table 1.- $B E T$ surface area, LOI, $\mathrm{I}_{\mathrm{D}} / \mathrm{I}_{\mathrm{D}}+\mathrm{I}_{\mathrm{G}}$ ratio from the Raman spectra and mercury retention in different fly ashes

\begin{tabular}{|c|c|c|c|c|c|}
\hline Sample & $\begin{array}{c}\text { BET } \\
\left(\mathrm{m}^{2} \mathrm{~g}^{-1}\right)\end{array}$ & $\begin{array}{l}\text { LOI } \\
(\%)\end{array}$ & $\begin{array}{c}I_{D} / I_{D}+I_{G} \\
(\%) \\
\end{array}$ & $\begin{array}{c}\mathrm{Hg}^{\mathrm{o}} \\
\text { (mgHg/g sorb) }\end{array}$ & $\begin{array}{c}\mathrm{HgCl}_{2} \\
\text { (mgHg/g sorb) }\end{array}$ \\
\hline CTA & 1.6 & 5.7 & -- & 12.1 & 2.53 \\
\hline $\mathrm{CTA}>150$ & 4.2 & 22.4 & 54.6 & 13.0 & 2.19 \\
\hline CTSR & 9.4 & 7.2 & --- & 25.4 & 12.3 \\
\hline $\mathrm{CTSR}>80$ & 17.6 & 54.2 & 55.2 & 27.2 & 16.6 \\
\hline CTES & 1.9 & 2.0 & --- & 1.50 & 3.20 \\
\hline $\mathrm{CTES}>200$ & 13.4 & 17.8 & 54.5 & 9.30 & 7.00 \\
\hline CTP & 6.7 & 3.8 & --- & 0.74 & 5.02 \\
\hline
\end{tabular}


Table 2.- Composition of fly ashes (\% vol.) determined via optical microscopy

\begin{tabular}{|c|c|c|c|c|c|c|c|c|c|c|c|c|c|}
\hline \multirow[t]{3}{*}{ SAMPLE } & \multicolumn{8}{|c|}{ ORGANIC FRACTION } & \multicolumn{5}{|c|}{ INORGANIC FRACTION } \\
\hline & \multicolumn{4}{|c|}{$\begin{array}{l}\text { ANISOTROPIC } \\
\text { COMPONENTS }\end{array}$} & \multicolumn{3}{|c|}{$\begin{array}{c}\text { ISOTROPIC } \\
\text { COMPONENTS }\end{array}$} & \multirow{2}{*}{$\begin{array}{c}\text { ANISO/ } \\
\text { ISO } \\
\text { Other } \\
\text { Org }\end{array}$} & & & & & \\
\hline & $\begin{array}{c}\text { Mass/dens } \\
\text { from } \\
\text { Vte }\end{array}$ & $\begin{array}{c}\text { Porous } \\
\text { from } \\
\text { Semi-Bit } \\
\text { Vte }\end{array}$ & $\begin{array}{c}\text { Mainly } \\
\text { Porous } \\
\text { from } \\
\text { Ite }\end{array}$ & $\begin{array}{l}\text { Undif } \\
\text { Frag }\end{array}$ & $\begin{array}{c}\text { Vesic } \\
\text { Porous } \\
\text { from } \\
\text { Vte }\end{array}$ & $\begin{array}{c}\text { Mass/dens } \\
\text { from } \\
\text { Ite }\end{array}$ & $\begin{array}{l}\text { Undif } \\
\text { Frag }\end{array}$ & & Glass & Quartz & Oxide & Mullite & $\begin{array}{c}\text { Other } \\
\text { MM }\end{array}$ \\
\hline CTA & 5.00 & 0.33 & 1.67 & 3.67 & 0.00 & 0.67 & 0.33 & 1.67 & 69.3 & 3.00 & 4.33 & 0.33 & 9.66 \\
\hline $\mathrm{CTA}>150$ & 22.0 & 0.67 & 4.33 & 0.67 & 0.00 & 2.67 & 0.00 & 0.00 & 65.3 & 0.00 & 1.33 & 0.00 & 3.00 \\
\hline CTSR & 1.00 & 5.33 & 0.33 & 4.33 & 0.33 & 1.00 & 1.67 & 0.00 & 79.0 & 0.33 & 4.00 & 0.00 & 2.67 \\
\hline $\mathrm{CTSR}>80$ & 8.33 & 23.0 & 3.67 & 4.67 & 5.33 & 7.00 & 1.00 & 1.00 & 44.0 & 0.33 & 0.67 & 0.00 & 1.00 \\
\hline CTES & 0.00 & 5.40 & 0.00 & 0.90 & 2.40 & 1.40 & 3.10 & 0.00 & 57.2 & 3.80 & 0.00 & 0.00 & 25.8 \\
\hline CTES $>200$ & 0.00 & 10.1 & 0.00 & 1.80 & 7.80 & 4.20 & 6.90 & 0.20 & 51.4 & 3.80 & 0.00 & 0.20 & 13.6 \\
\hline CTP & 0.33 & 1.32 & 0.00 & 5.63 & 0.00 & 0.00 & 0.00 & 0.00 & 58.6 & 0.33 & 28.5 & 0.00 & 5.30 \\
\hline
\end{tabular}

Mass/dens; massive/dense, Vte; vitrinite, Bit; bituminous, Ite.; inertinite, Undif; undifferentiated, Frag; fragments, Vesic; vesiculated, Org; organic, MM; mineral matter 


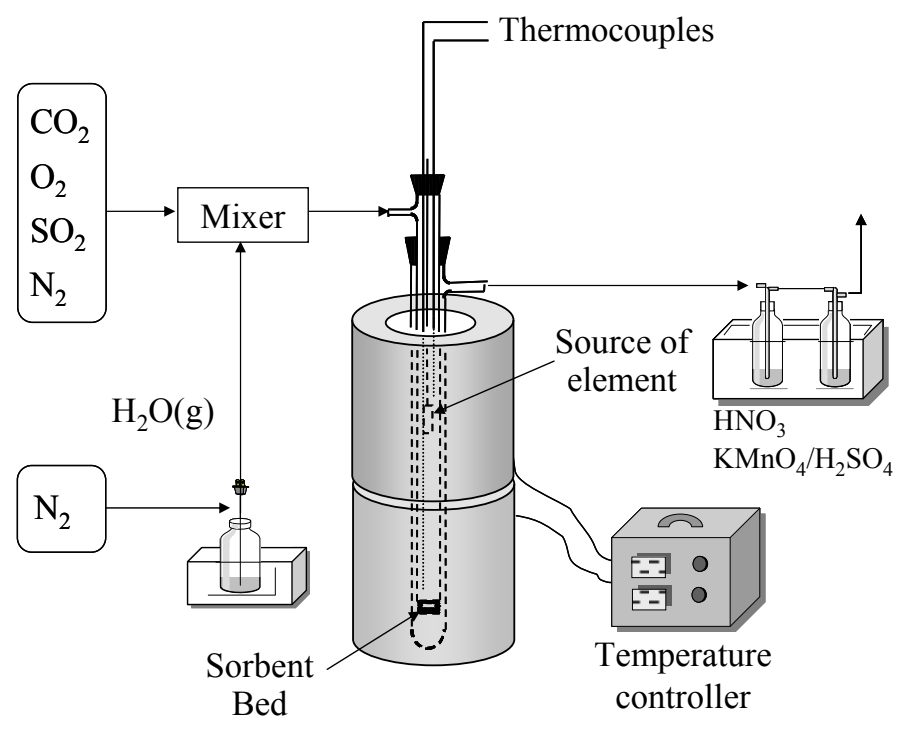

Fig 1. Schematic diagram of the experimental device 

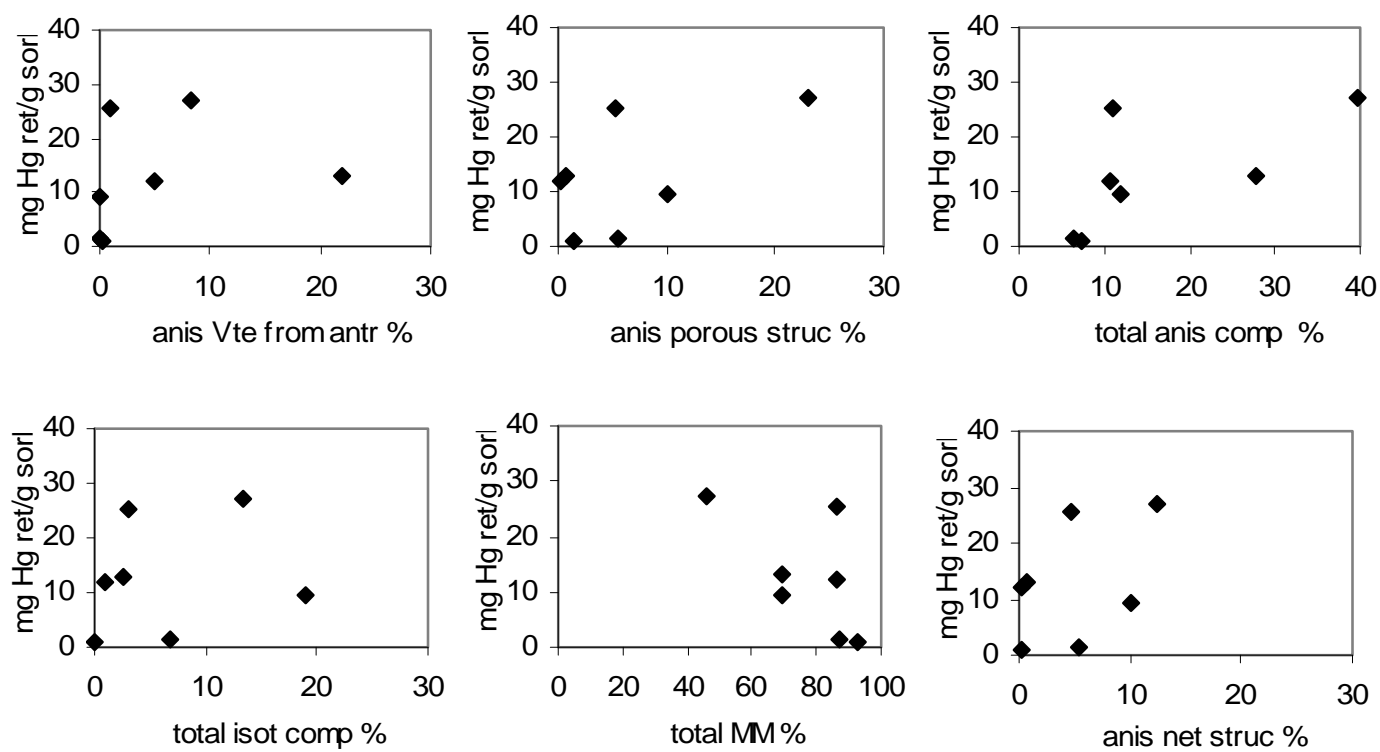

Fig 2.- Anisotropic components of vitrinite from anthracite, anisotropic porous structures, total anisotropic components, total isotropic components, total mineral matter and anisotropic network structures versus mercury retention from $\mathrm{Hg}^{0}$ evaporation 

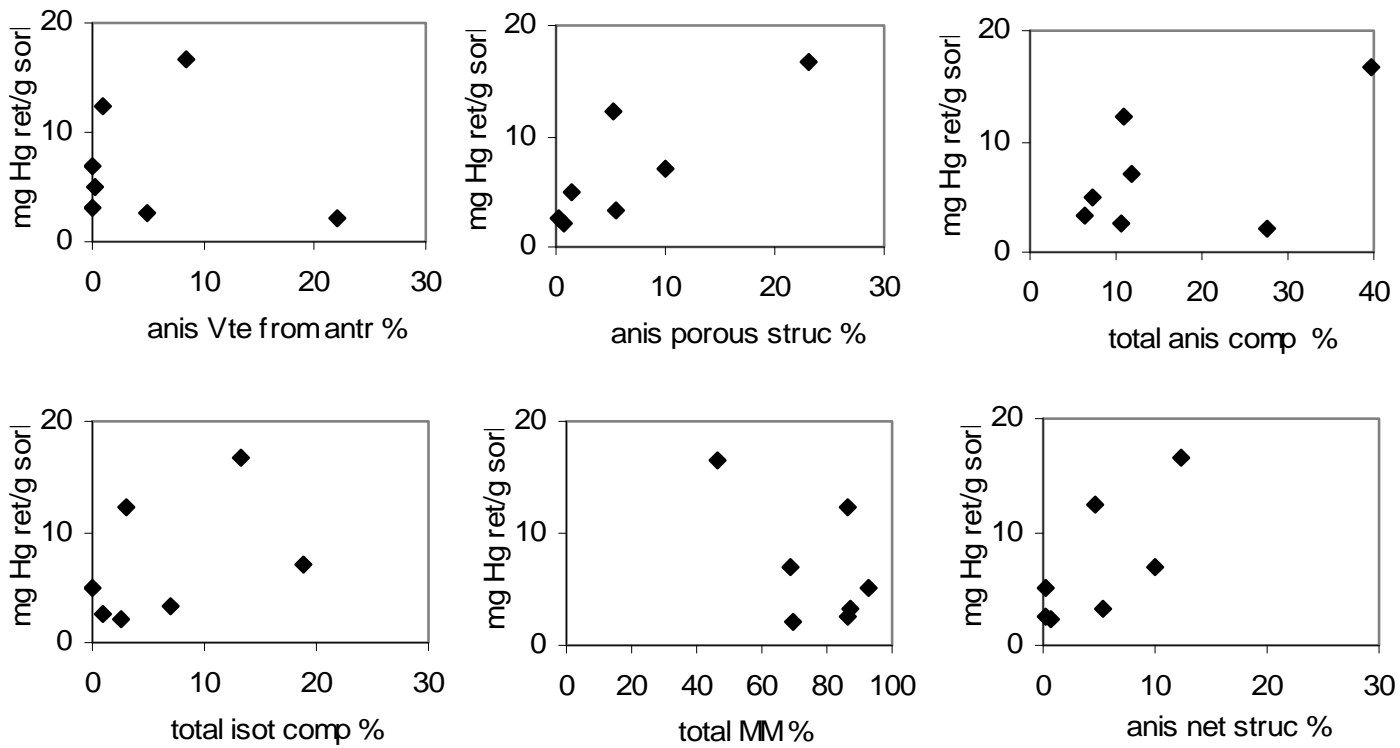

Fig 3.- Anisotropic components of vitrinite from anthracite, anisotropic porous structures, total anisotropic components, total isotropic components, total mineral matter and anisotropic network structures versus mercury retention from $\mathrm{HgCl}_{2}$ evaporation 

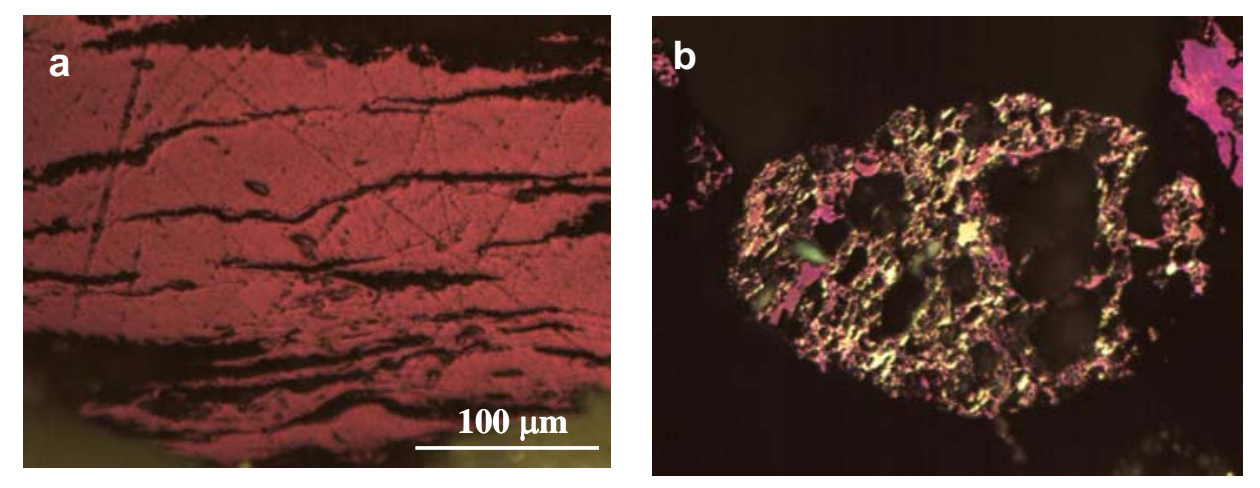

Fig 4.- Microphotographs of some examples of anisotropic fly ash carbons. Optical microscopy, pictures taken in oil immersion (50x objective) with polarized light and retarder plate. a)- Anisotropic and unfused fly ash carbon typical of the combustion of anthracitic vitrinite and b)- Anisotropic, fused and porous fly ash carbon from a lower rank coal 


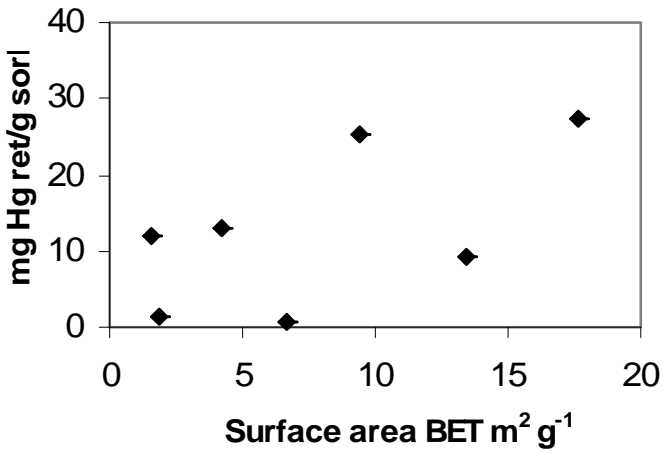

(a)

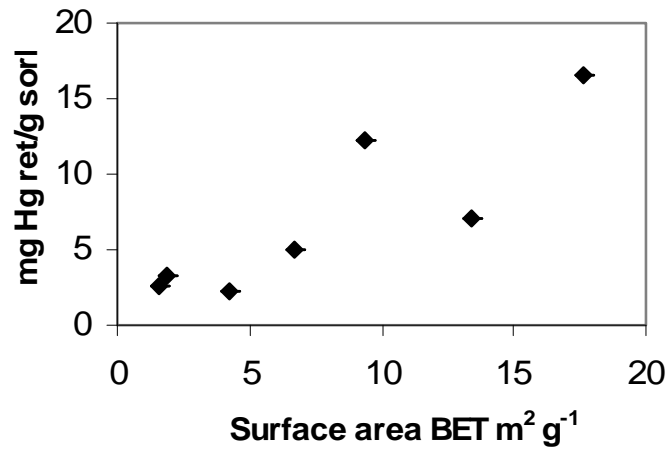

(b)

Fig 5.- BET surface area versus mercury retention from $\mathrm{Hg}^{0}$ (a) and $\mathrm{HgCl}_{2}$ (b) 